\title{
Cabergoline treatment rapidly improves gonadal function in hyperprolactinemic males: a comparison with bromocriptine
}

Michele De Rosa, Annamaria Colao, Antonella Di Sarno, Diego Ferone, Maria Luisa Landi, Stefano Zarrilli, Luigi Paesano, Bartolomeo Merola and Gaetano Lombardi

Department of Endocrinology and Molecular and Clinical Oncology, Federico II University, via S Pansini 5, 80131 Naples, Italy

(Correspondence should be addressed to M De Rosa, Department of Endocrinology and Molecular and Clinical Oncology, Federico II University, via Belsito 19, 80123 Naples, Italy)

\begin{abstract}
This study evaluated the effects of chronic treatment with cabergoline (CAB), a new, potent and longlasting ergoline-derived dopamine agonist, on seminal fluid parameters and sexual and gonadal function in hyperprolactinemic males in comparison with the effect of bromocriptine (BRC) treatment.

Seventeen males with macroprolactinoma were treated with $\mathrm{CAB}$ at a dose of $0.5-1.5 \mathrm{mg} / \mathrm{week}$ $(n=7)$, or BRC at a dose of $5-15 \mathrm{mg} /$ day $(n=10)$ for 6 months. Baseline prolactin (PRL) was $925.7 \pm 522.6 \mu \mathrm{g} / \mathrm{l}$ in the CAB-treated group and $1059.4 \pm 297.6 \mu \mathrm{g} / \mathrm{l}$ in the BRC-treated group. All the patients suffered from libido impairment, ten from reduced sexual potency, and six had infertility. In five patients provocative bilateral galactorrhea was found.

Seminal fluid analysis, functional seminal tests and penis rigidity and tumescence, measured by nocturnal penile tumescence (NPT) using Rigiscan equipment, were assessed before and after 1, 3 and 6 months of $\mathrm{CAB}$ or BRC treatment. Hormone profiles were assessed before and after 15, 30, 60, 90 and 180 days of both treatments.

Before treatment, all patients had a low sperm count with oligoasthenospermia, reduced motility and rapid progression with an abnormal morphology and decreased viability, and a low number of erections. After 1 month, serum PRL levels were significantly reduced in both groups of patients $(20.6 \pm 6.6 \mu \mathrm{g} / \mathrm{l}$ during $\mathrm{CAB}$ and $256.3 \pm 115.1 \mu \mathrm{g} / \mathrm{l}$ during BRC treatment) and were normalized after 6 months in all patients (CAB: $7.9 \pm 2.2 \mu \mathrm{g} / \mathrm{l}$; BRC: $16.7 \pm 1.8 \mu \mathrm{g} / \mathrm{l})$. After 6 months, a significant increase of number, total motility, rapid progression and normal morphology was recorded in patients treated with both $\mathrm{CAB}$ and $\mathrm{BRC}$. An increase in the number of erections during the first 3 months of both treatments was noted by NPT. However, the improvements in seminal fluid parameters and sexual function were more evident and rapid in patients treated with $\mathrm{CAB}$. The number of erections was normalized after 6 months of treatment in all patients submitted to CAB treatment, and in all patients but one treated by BRC. In addition, a significant increase of serum testosterone (from $3.7 \pm 0.3$ to $5.3 \pm 0.2 \mu \mathrm{g} / \mathrm{l}$ ) and dihydrotestosterone (from $0.4 \pm 0.1$ to $1.1 \pm 0.1 \mathrm{nmol} / \mathrm{l}$ ) was recorded. At the beginning of treatment, mild side-effects were recorded in two patients after $\mathrm{CAB}$ and mild-to-moderate side-effects in five patients after BRC administration.

The treatment with CAB normalized PRL levels, improving gonadal and sexual function and fertility in males with prolactinoma, earlier than did BRC treatment, providing good tolerability and excellent patient compliance to medical treatment.
\end{abstract}

European Journal of Endocrinology 138 286-293

\section{Introduction}

The impairment of gonadal function is the most common clinical finding of hyperprolactinemia in both sexes. In particular, elevated prolactin (PRL) levels were shown in about $1-5 \%$ of oligospermic men without demonstrable pituitary tumors $(1,2)$. In the last two decades it has been widely demonstrated that the medical treatment of hyperprolactinemia with dopamine agonists normalizes serum PRL levels and reduces tumoral mass, so restoring gonadal and sexual function in most patients (3-9). However, in the world literature, data on semen analysis in hyperprolactinemic patients during dopamine agonist treatment are lacking. In a recent study we showed that a 1-year treatment with CV 205-502 normalized serum PRL levels and restored gonadal function with disappearance of libido impairment and of several functional abnormalities of the ejaculates (10). This result is apparently in disagreement with another study reporting the lack of significant change in seminal fluid parameters during bromocriptine (BRC) therapy (3). However, no significant change in 
seminal fluid parameters, except an increase in sperm count, was found during the first months of CV 205-502 therapy, in spite of suppressed PRL concentrations. This indicated that a long period of treatment is required to restore the gonadal function in hyperprolactinemic males. Cabergoline (CAB), a synthetic ergoline which is a selective and long-lasting $\mathrm{D}_{2}$ dopamine agonist that inhibits PRL secretion both in healthy and hyperprolactinemic subjects, has been recently introduced into the therapeutic armamentarium for hyperprolactinemic syndromes. $\mathrm{CAB}$ is characterized by a duration of action as long as 21 days after a single oral dose of $0.3-1 \mathrm{mg}$ (11-14). Moreover, $\mathrm{CAB}$ has been shown to be more effective and better tolerated than BRC in a multicenter, randomized 24-week trial in 459 hyperprolactinemic women (15) and in a few patients with macroprolactinoma (16).

Since $\mathrm{CAB}$ was shown to notably reduce prolactinoma volume $(17,18)$, and was even effective in prolactinomas resistant to BRC and CV 205-502 (19), this study was designed to evaluate whether chronic treatment with $\mathrm{CAB}$ could successfully restore gonadal and sexual function in males with macroprolactinoma, and the time-course of this effect. To this end, the results of $\mathrm{CAB}$ treatment were compared with those obtained using BRC in a similar group of patients. Moreover, since hyperprolactinemic males suffer from deficiency of libido and potency, though not always reaching complete impotence, their nocturnal penile tumescence (NPT) records were obtained.

\section{Patients and methods}

\section{Patients}

Among 26 males admitted to our Department for hyperprolactinemia from 1993 to 1996, 17 (aged 2238 years) with macroprolactinoma gave their informed consent to participate in this open-label study. All the patients suffered from libido impairment for at least 6 12 months, and ten from reduced sexual potency; six had infertility and in five provocative bilateral galactorrhea was recorded. Visual impairment was present in four patients. Because of different drug availabilities during recent years, ten were treated with BRC for 6 months while the remaining seven patients were treated with CAB. Four of seven CAB-treated patients (nos 1-3 and 5, Table 1) were previously treated also with BRC for a few days (less than 2 weeks) but the drug was withdrawn because of side-effects. Table 1 summarizes patient profiles at study entry.

\section{Study protocol}

All of the patients were subjected to a clinical examination with ECG and complete blood and urine analysis. Serum PRL levels, assessed in multiple sampling over $6 \mathrm{~h}(0800-1400 \mathrm{~h})$, and follicle-stimulating hormone (FSH), luteinizing hormone (LH), testosterone and dihydrotestosterone (DHT) concentrations were assayed before and after 15, 30, 60, 90 and 180 days of $\mathrm{CAB}$ or BRC treatment. Semen and NPT analysis were carried out before and after 30,90 and 180 days of CAB or BRC treatment.

\section{Treatment protocol}

The treatment with $\mathrm{CAB}$ was started at a dose of $0.5 \mathrm{mg}$ once weekly for 15 days; afterwards the dose was increased to up to $0.5 \mathrm{mg}$ twice weekly. Subsequently, on the basis of PRL values, the dose was increased to $1.5 \mathrm{mg}$ /week in one patient (no. 2, Table 1) to achieve PRL level suppression. The treatment with BRC was started at a dose of $1.25 \mathrm{mg}$ twice daily for 1 week, and then was increased to $2.5 \mathrm{mg}$ twice daily for 3 weeks. Subsequently, on the basis of PRL values, the dose was increased to $10 \mathrm{mg} /$ day in four patients (nos $1,7,8$, 10 , Table 1 ), and to $15 \mathrm{mg}$ /day in one patient (no. 6 , Table 1) to achieve PRL level suppression.

\section{Methods}

PRL, FSH, LH, testosterone and DHT levels were assessed by RIA using available commercial kits. Seminal fluid evaluation was performed after at least 3 days of abstinence, and at least twice at study entry in line with guidelines of a World Health Organization (WHO) laboratory manual (18). The evaluation of number and motility of the spermatozoa was carried out in a Makler Counting Chamber $(\times 40)$; the morphology was analyzed after dilution (1:1) with PBS and Giemsa stain. Moreover, some functional sperm tests, such as the eosin test (ET), the hyposmotic swelling test (HOS) and the cervical mucus penetration test (CMPT), were performed as reported elsewhere (19). The normal ranges of hormone levels, and sperm patterns according to the WHO manual (18), are reported in the footnote to Table 2.

The erectile capability of our patients during both treatments was evaluated by NPT, using Rigiscan equipment provided by Dacomed (Minneapolis, USA) (20). This device allows monitoring of the duration, frequency and degree of both rigidity and tumescence during sleep. We performed three tests during three different nights; the best record was used for this study. As according to the literature (21), we considered normal one episode of rigidity over the $70 \%$ for almost $10 \mathrm{~min}$ with a variation of tumescence of $30 \mathrm{~mm}$ at the base and of $20 \mathrm{~mm}$ at the tip of penis. As far as frequency was concerned, three episodes per night were considered as the lowest normal value.

\section{Radiological examinations}

The computed tomography (CT) scan was carried out by a third generation scanner with $3.5 \mathrm{~s}$ acquisition times, $1.5 \mathrm{~mm}$ thickness axial and coronal sections, and 


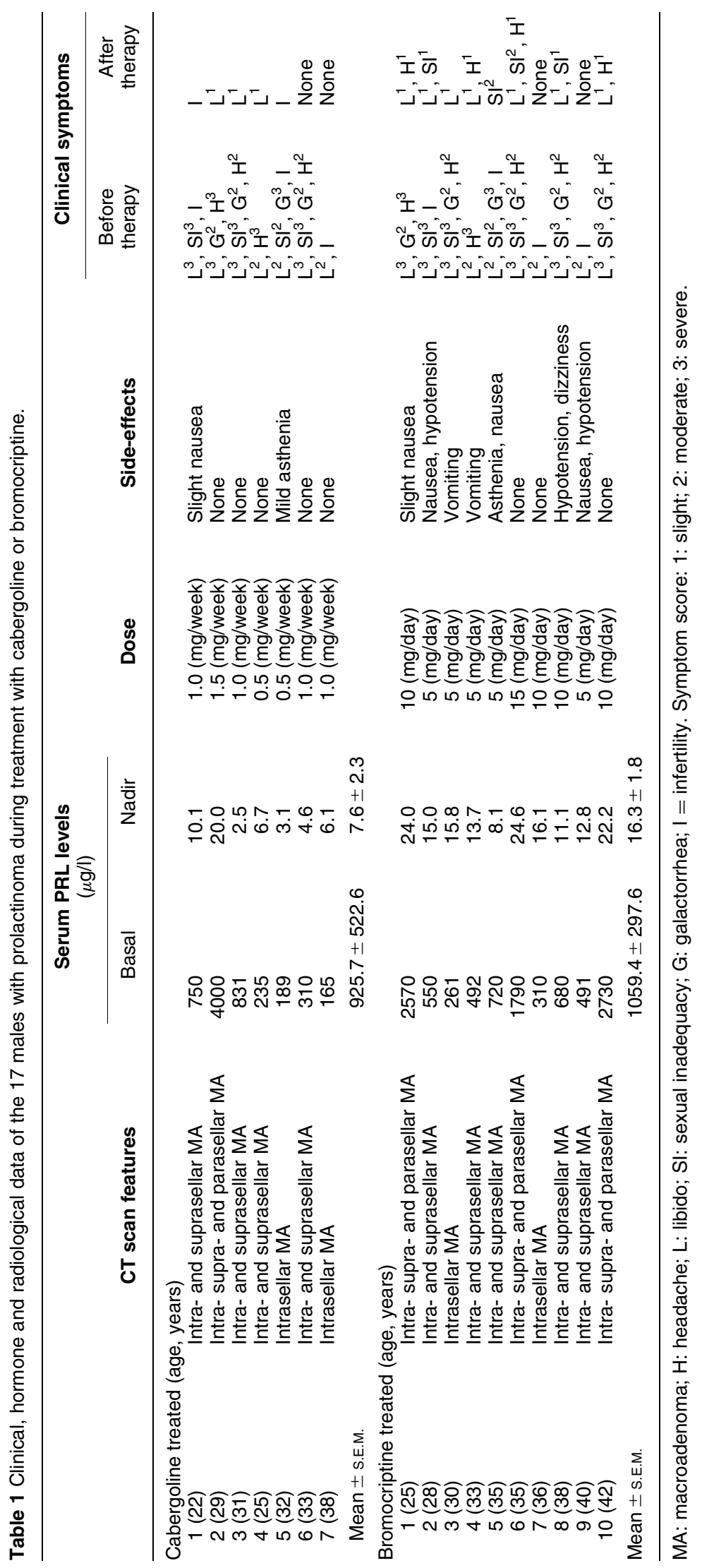


Table 2 Hormone profiles and seminal fluid parameters ( \pm S.E.M.) at study entry in 17 males with macroprolactinoma who were to undergo chronic treatment with cabergoline or bromocriptine.

\begin{tabular}{lcc}
\hline & $\begin{array}{c}\text { Cabergoline-treatment } \\
\text { patients } \\
(n=7)\end{array}$ & $\begin{array}{c}\text { Bromocriptine-treatment } \\
\text { patients } \\
(n=10)\end{array}$ \\
\hline Serum hormone levels & $925.7 \pm 522.6$ & $1059.4 \pm 297.6$ \\
PRL $(\mu \mathrm{g} / \mathrm{l})$ & $3.7 \pm 0.3$ & $3.2 \pm 0.2$ \\
Testosterone $(\mu \mathrm{g} / \mathrm{l})$ & $0.40 \pm 0.10$ & $0.37 \pm 0.06$ \\
DHT (mmol/l) & $6.5 \pm 1.8$ & $5.9 \pm 2.1$ \\
FSH (IU/l) & $5.2 \pm 3.1$ & $5.3 \pm 2.8$ \\
LH (IU/l) & & \\
Seminal fluid parameters & $5.8 \pm 0.2$ & $6.1 \pm 0.3$ \\
Concentration (10\%/ml) & $20.0 \pm 1.0$ & $22.1 \pm 1.3$ \\
Motility: total (\%) & $10.0 \pm 2.0$ & $12.1 \pm 1.2$ \\
Rapid progression (\%) & $30.0 \pm 5.0$ & $30.6 \pm 1.2$ \\
Morphology: normal (\%) & $45.0 \pm 3.0$ & $40.3 \pm 1.2$ \\
Immature germ cells (\%) $(\%)$ & $36.1 \pm 0.5$ \\
Viability (\%) & $35.0 \pm 2.0$ & $25.1 \pm 1.2$ \\
HOS (\%) & $28.0 \pm 1.0$ & $9 \pm 1.0$ \\
CMPT (mm) & $7 \pm 0.5$ & $1.9 \pm 0.1$ \\
Zinc ( $\mu$ mol/ejaculate) & $1.8 \pm 0.2$ & $6.5 \pm 0.5$ \\
Citric acid $(\mu$ mol/ejaculate) & $6.0 \pm 0.3$ & $202 \pm 10$ \\
Acid phosphate (U/ejaculate) & $200 \pm 15$ & $11 \pm 0.1$ \\
Fructose $(\mu$ mol/ejaculate) & $10 \pm 1.0$ & \\
\hline
\end{tabular}

Normal ranges: PRL 5-25 $\mu \mathrm{g} / \mathrm{l}$; testosterone 3.5-9 $\mu \mathrm{g} / \mathrm{l}$; DHT 0.4-1.6 mmol/l; FSH and LH 5$18 \mathrm{IU} / \mathrm{l}$; spermatozoa concentration $>20 \times 10^{6} \mathrm{ml}$; sperm motility at $1 \mathrm{~h} 53.8-74.6 \%$; forward progression 33.2-67.6\%; normal morphology $>30 \%$; viability $>60 \%$; HOS $>60 \%$; CMPT $>30 \mathrm{~mm}$; zinc $>2.4 \mu \mathrm{mol} /$ ejaculate; citric acid $>52 \mu \mathrm{mol} /$ ejaculate; acid phosphatase $>200$ U/ejaculate; fructose $>13 \mu \mathrm{mol} /$ ejaculate.

scout-view. CT was performed before and after intravenous infusion of contrast medium. Magnetic resonance imaging (MRI) was carried out by a super conductive magnetic resonance (0.5 tesla) and superficial coil in axial, coronal and sagittal sections. The acquisitions were spin echo with $1000 \mathrm{~ms}$ repetition time and 40-120 ms echo time of $21 \mathrm{~ms}$. CT and/or MRI were carried out before and 6 months after $\mathrm{CAB}$ or $\mathrm{BRC}$ treatment. Prolactinoma shrinkage was considered significant when a reduction in tumor size greater than 30\% (with respect to baseline size) was documented at MRI or CT scan.

Visual field examination was performed by Goldmann-Friedmann perimetry before and 6 months after treatment in patients with visual field defects.

\section{Statistical analysis}

Data are shown as means \pm s.e.M. The results were analyzed by Student's $t$-test for paired data for intragroup analysis, and by ANOVA followed by the NewmannKeuls test for intergroup analysis. Significance was set at $5 \%$.

\section{Results}

At study entry, no difference was found between CABtreated and BRC-treated patients as far as hormonal assessment and sexual and gonadal function were concerned (Table 2). The long-term treatments with
$\mathrm{CAB}$ and $\mathrm{BRC}$ normalized serum PRL levels in all patients, as shown in Fig. 1. In both CAB- and BRC-treated groups, serum PRL levels significantly and progressively decreased from baseline values of $925 \pm 522 \mu \mathrm{g} / \mathrm{l}$ and $1059 \pm 297 \mu \mathrm{g} / \mathrm{l}$ to nadir values of $7.6 \pm 2.3 \mu \mathrm{g} / \mathrm{l}$ and $16.3 \pm 1.8 \mu \mathrm{g} / \mathrm{l}$ respectively (Table 1). However, the decrease of PRL levels was more rapid during $\mathrm{CAB}$ than during $\mathrm{BRC}$ treatment; in fact, after 1 month PRL levels were normalized in six of seven patients during $\mathrm{CAB}$ treatment (nadir 20.6 $\pm 6.6 \mu \mathrm{g} / \mathrm{l}$ ) and in only one patient during BRC treatment (nadir $256.3 \pm 115.1 \mu \mathrm{g} / \mathrm{l}, P<0.005)$. At the end of 6 months of treatment all patients had normal PRL levels (Fig. 1). At study entry, serum testosterone and DHT levels were low in all patients, being lower than normal in 8 of 17 patients, and progressively and significantly increased during both treatments (Figs 2 and 3). In fact, serum DHT levels increased from $0.4 \pm 0.1$ to $1.1 \pm 0.4 \mathrm{nmol} / \mathrm{l}$ $(P<0.001)$ after $\mathrm{CAB}$ treatment and from $0.37 \pm 0.06$ to $1.17 \pm 0.04 \mathrm{nmol} / \mathrm{l}(P<0.001)$ after BRC. Serum FSH and LH levels slightly increased during treatment; however, baseline and in-treatment levels were normal except in 4 of 17 patients with macroprolactinoma (data not shown).

All patients reported a remarkable improvement of sexual potency and libido after only the first 2 months of $\mathrm{CAB}$ treatment. At clinical examination disappearance of galactorrhea was seen in all four patients after 3-6 months of treatment (Table 1). In both groups of 

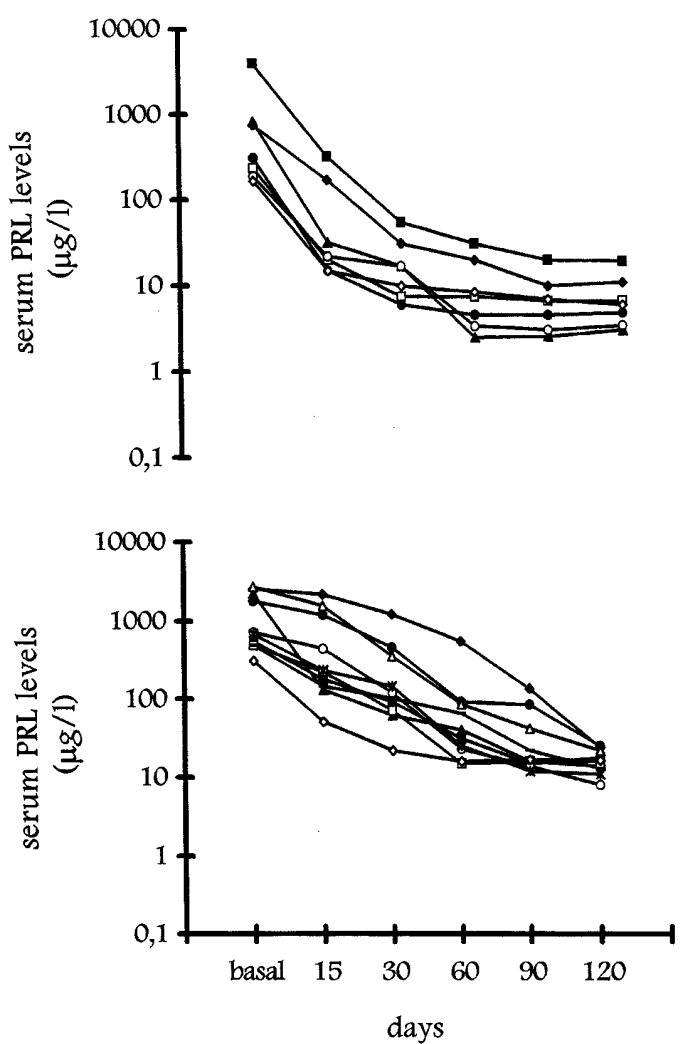

Figure 1 Serum PRL profiles in the seven patients before and after CAB treatment (upper panel) and in the ten patients before and after BRC treatment (lower panel).

patients, NPT analysis showed a significantly reduced rigidity and tumescence of the penis at the beginning of treatment; after both treatments, rigidity and tumescence normalized in all patients (Table 3).

Before treatment, the ejaculates showed decreased sperm count, motility, viability, and biochemical and functional patterns. During treatment a significant increase of sperm count, motility, viability and functional activity was noted. In particular, the improvement of sperm count was observed after 3 months of $\mathrm{CAB}$ treatment and persisted until the 6th month. During BRC treatment sperm count, motility, viability and functional test remained unmodified in the 1st month of therapy, but progressively increased after the 3rd month until the 6th month (Table 4). Two patients fathered children during $\mathrm{CAB}$ treatment.

A significant shrinkage of tumor mass was detected by CT scan and/or MRI in five of seven patients $(71.4 \%)$ treated with $\mathrm{CAB}$ and in six of ten $(60 \%)$ treated with BRC. Improvement of the visual field was noted in the patients with visual field defects (Table 1).

Lastly, side-effects were reported by two and seven patients at the beginning of $\mathrm{CAB}$ and $\mathrm{BRC}$ treatment respectively. During $\mathrm{CAB}$ treatment, side-effects were milder and shorter lasting, and did not require any
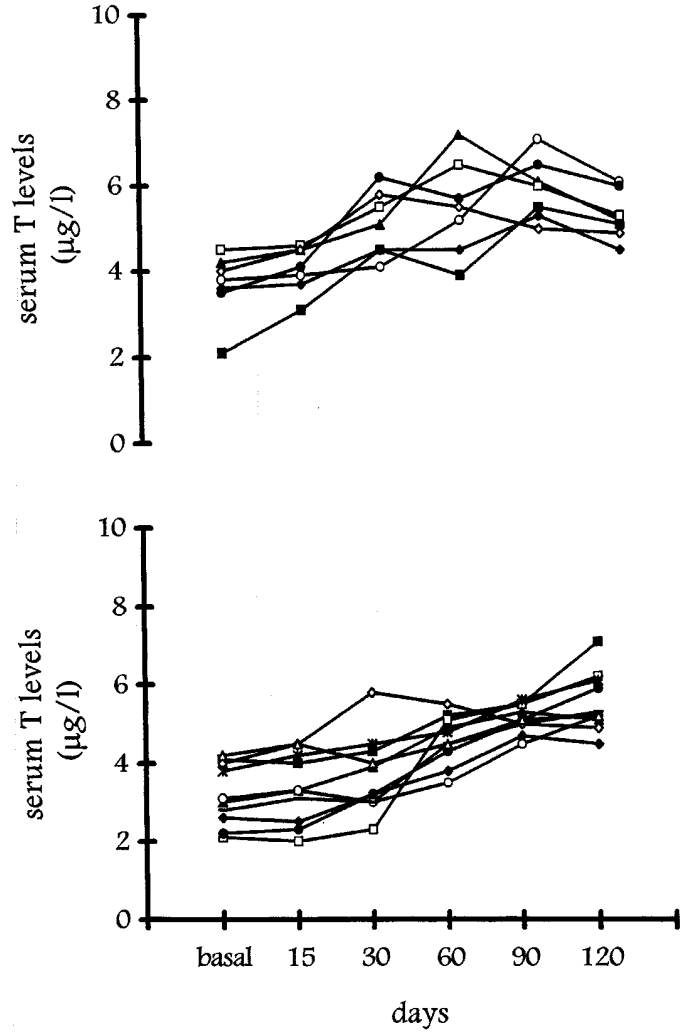

Figure 2 Serum testosterone $(T)$ profiles in the seven patients before and after CAB treatment (upper panel) and in the ten patients before and after BRC treatment (lower panel).

specific treatment. Conversely, in two patients treated with BRC, the dose of BRC was reduced for a few days and thereafter progressively increased to therapeutic values. Two to three days of bed rest were required in two patients (nos 2 and 9) showing postural hypotension after drug administration at the beginning of BRC treatment.

\section{Discussion}

In recent years, $\mathrm{CAB}$ has been shown to be highly effective in normalizing serum PRL levels at low doses (11-16), with excellent patient compliance. Moreover, $\mathrm{CAB}$ was effective in patients with prolactinoma resistant to BRC and CV 205-502 (17). However, although the recovery of gonadal function and fertility in females has been widely documented, no data had been reported so far on sexual and gonadal function in hyperprolactinemic males during $\mathrm{CAB}$ treatment. Thus, we evaluated whether $\mathrm{CAB}$ was able to restore gonadal function in a few hyperprolactinemic males, and the time-course of this result. In the present report, all seven patients treated with $\mathrm{CAB}$ showed a remarkable improvement of libido and potency, and an improvement in sperm parameters, after only 3 months of treatment, while in the ten patients treated with BRC 

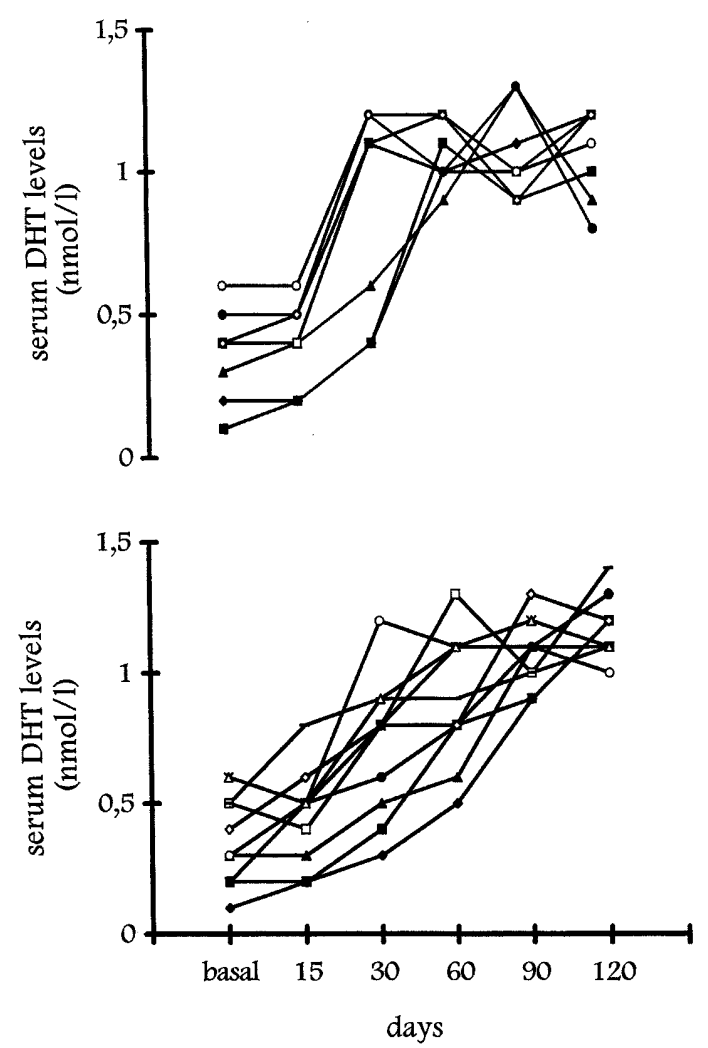

Figure 3 Serum DHT profiles in the seven patients before and after $\mathrm{CAB}$ treatment (upper panel) and in the ten patients before and after BRC treatment (lower panel).

sperm parameters improved later. On the other hand, serum PRL levels were normalized in all 17 patients, but normoprolactinemia was reached after 2 months in the seven patients treated with $\mathrm{CAB}$ and after 6 months in the ten treated with BRC. Moreover, in CAB-treated patients, the percentage of immature germ cells became significantly reduced, while sperm viability, swollen tails and penetration in bovine cervical mucus significantly increased during the first 3 months of treatment. By contrast, the biochemical parameters of seminal fluid were not significantly changed.

The improvement of seminal fluid analysis after longterm $\mathrm{CAB}$ treatment occurred fast in comparison to the notable results obtained after CV 205-502 treatment in a different series of patients (17) and to the results obtained after BRC treatment. This beneficial effect of $\mathrm{CAB}$ could be due either to the peculiar pharmacokinetic profile of $\mathrm{CAB}$, characterized by a prolonged halflife and a notably slow elimination from highly perfused tissues like the pituitary (22) or to the fact that in this series were included patients untreated or who had received BRC only for a few days. Therefore, these patients could better respond to the rapid serum PRL normalization. The positive effect of $\mathrm{CAB}$ treatment on gonadal and sexual function in hyperprolactinemic
Table 3 Rigiscan analysis in 17 males with prolactinoma during chronic treatment with cabergoline or bromocriptine. The nocturnal penile tumescence is expressed as best record of the number of episodes/night.

\begin{tabular}{ccccc}
\hline & & \multicolumn{3}{c}{$\begin{array}{c}\text { Follow-up } \\
\text { during treatment } \\
\text { (months) }\end{array}$} \\
\cline { 2 - 5 } & $\begin{array}{c}\text { Baseline } \\
\text { evaluation }\end{array}$ & $\mathbf{1}$ & $\mathbf{3}$ & $\mathbf{6}$ \\
\hline Cabergoline treated & & & & \\
1 & 1 & 2 & 3 & 4 \\
2 & 1 & 2 & 3 & 5 \\
3 & 0 & 0 & 2 & 3 \\
4 & 0 & 1 & 2 & 3 \\
5 & 1 & 1 & 2 & 4 \\
6 & 0 & 1 & 2 & 4 \\
7 & 1 & 1 & 2 & 5 \\
Bromocriptine treated & & & & \\
1 & 1 & 1 & 2 & 3 \\
2 & 0 & 1 & 3 & 4 \\
3 & 1 & 1 & 2 & 3 \\
4 & 1 & 1 & 1 & 2 \\
5 & 1 & 2 & 3 & 4 \\
6 & 1 & 1 & 2 & 3 \\
7 & 0 & 0 & 1 & 3 \\
8 & 0 & 0 & 1 & 3 \\
9 & 0 & 0 & 1 & 3 \\
10 & 0 & 0 & 1 & 3 \\
\hline
\end{tabular}

males is closely correlated to the effect played by PRL not only on sexual steroid secretion but also on spermatogenesis. In fact, it has been recently demonstrated that PRL receptors are present in all stages of the cycle of the seminiferous epithelium, the surface of Leydig and Sertoli cells, all phases of spermatogonia and spermatocytes in male rats (23), suggesting that PRL plays a pivotal role in the development of spermatogenesis. In addition, several older studies on animals demonstrated that normal serum PRL levels are required for a normal testicular function and growth of accessory sex organs, since PRL acts synergistically with $\mathrm{LH}$ and testosterone $(24,25)$ and it regulates the levels of the testosterone precursors for conversion under the influence of LH (25). On the other hand, hyperprolactinemia suppressed LH pulse frequency in castrated male rats (26) and decreased testosterone levels by inhibiting gonadotropin-releasing hormone and, consequently, gonadotropin secretion in men (27). Thus, hyperprolactinemia affects male gonadal function, acting at different levels. As a consequence, hyperprolactinemia affects seminal fluid quality through many different mechanisms, in particular causing spermiogenic arrest and impairing sperm motility and/or quality. This induces cytological findings of sperm characteristics similar to that observed in the prepubertal testis (2). The rapid normalization of gonadotropin and testosterone secretion improved either sperm maturation or the function of the accessory glands that are under the direct action of 
Table 4 Seminal fluid parameters ( \pm S.E.M.) in males with prolactinoma during chronic treatment with cabergoline or bromocriptine.

\begin{tabular}{|c|c|c|c|c|}
\hline & \multirow{2}{*}{$\begin{array}{l}\text { Baseline } \\
\text { evaluation }\end{array}$} & \multicolumn{3}{|c|}{$\begin{array}{l}\text { Follow-up during treatment } \\
\text { (months) }\end{array}$} \\
\hline & & 1 & 3 & 6 \\
\hline \multicolumn{5}{|l|}{ Cabergoline treated } \\
\hline Concentration $\left(10^{6} / \mathrm{ml}\right)$ & $5.8 \pm 0.2$ & $6.2 \pm 0.1$ & $8.9 \pm 0.4^{a}$ & $18.5 \pm 1.0^{\mathrm{a}, \mathrm{b}}$ \\
\hline Motility: total (\%) & $20 \pm 1.0$ & $25 \pm 0.5^{\mathrm{a}}$ & $45 \pm 0.5^{\mathrm{a}}$ & $55 \pm 3.0^{a, b}$ \\
\hline Rapid progression (\%) & $10 \pm 2.0$ & $11 \pm 1.0$ & $20 \pm 3.0^{\mathrm{a}}$ & $43 \pm 1.5^{\mathrm{a}, \mathrm{b}}$ \\
\hline Morphology: normal (\%) & $30 \pm 5.0$ & $35 \pm 7.0$ & $40 \pm 5.5$ & $50 \pm 2.5^{\mathrm{a}}$ \\
\hline Immature germ cells (\%) & $45 \pm 3.0$ & $43 \pm 5.0$ & $31 \pm 6.0$ & $15 \pm 2.0^{a, b}$ \\
\hline Viability (\%) & $35 \pm 2.0$ & $35 \pm 1.0$ & $43 \pm 2.0^{\mathrm{a}}$ & $60 \pm 5.0^{\mathrm{a}, \mathrm{b}}$ \\
\hline HOS (\%) & $28 \pm 1.0$ & $30 \pm 1.5$ & $48 \pm 5.0^{\mathrm{a}}$ & $61 \pm 2.0^{\mathrm{a}, \mathrm{b}}$ \\
\hline CMPT (mm) & $7 \pm 0.5$ & $7 \pm 1.0$ & $14 \pm 2.0$ & $24 \pm 1.0^{a, b}$ \\
\hline Zinc (mmol/ejaculate) & $1.8 \pm 0.2$ & $1.9 \pm 0.1$ & $2.5 \pm 0.2^{\mathrm{a}}$ & $2.4 \pm 0.1^{\mathrm{a}}$ \\
\hline Citric acid (mmol/ejaculate) & $6.0 \pm 0.3$ & $6.5 \pm 0.4$ & $7.0 \pm 0.2$ & $6.3 \pm 0.2$ \\
\hline Acid phosphates (U/ejaculate) & $200 \pm 15$ & $210 \pm 13$ & $240 \pm 13$ & $230 \pm 11$ \\
\hline Fructose (mmol/ejaculate) & $10 \pm 1.0$ & $12 \pm 1.5$ & $15 \pm 2.0$ & $18 \pm 3.0^{\mathrm{a}}$ \\
\hline \multicolumn{5}{|l|}{ Bromocriptine treated } \\
\hline Concentration $\left(10^{6} / \mathrm{ml}\right)$ & $6.1 \pm 0.3$ & $6.0 \pm 0.2$ & $6.2 \pm 0.4$ & $8.9 \pm 1.2^{\mathrm{a}, \mathrm{b}}$ \\
\hline Motility: total (\%) & $22.1 \pm 1.3$ & $22.3 \pm 0.2$ & $23.2 \pm 1.5$ & $45.6 \pm 4.3^{\mathrm{a}, \mathrm{b}}$ \\
\hline Rapid progression (\%) & $12.1 \pm 1.3$ & $18.3 \pm 1.1^{\mathrm{a}}$ & $20.1 \pm 0.4^{\mathrm{a}}$ & $30.2 \pm 1.5^{\mathrm{a}, \mathrm{b}}$ \\
\hline Morphology: normal (\%) & $30.6 \pm 1.2$ & $32.3 \pm 2.1$ & $37.8 \pm 1.2^{\mathrm{a}}$ & $48.3 \pm 2.1^{\mathrm{a}, \mathrm{b}}$ \\
\hline Immature germ cells $(\%)$ & $40.3 \pm 1.2$ & $35.2 \pm 1.2^{\mathrm{a}}$ & $30.1 \pm 2.1^{\mathrm{a}}$ & $25.1 \pm 1.0^{\mathrm{a}, \mathrm{b}}$ \\
\hline Viability (\%) & $36.1 \pm 0.5$ & $35.3 \pm 2.1$ & $38.1 \pm 1.5$ & $42.3 \pm 3.4$ \\
\hline $\operatorname{HOS}(\%)$ & $25.1 \pm 1.2$ & $25.3 \pm 3.2$ & $32.1 \pm 3.1$ & $57.1 \pm 2.3^{\mathrm{a}, \mathrm{b}}$ \\
\hline CMPT $(\mathrm{mm})$ & $9.0 \pm 1.0$ & $11.3 \pm 1.5$ & $12.7 \pm 4.1$ & $15.3 \pm 1.0$ \\
\hline Zinc (mmol/ejaculate) & $1.9 \pm 0.1$ & $1.8 \pm 0.2$ & $2.1 \pm 1.0$ & $2.1 \pm 0.9$ \\
\hline Citric acid (mmol/ejaculate) & $6.5 \pm 0.5$ & $6.4 \pm 0.7$ & $6.8 \pm 1.0$ & $7.0 \pm 1.2$ \\
\hline Acid phosphatase (U/ejaculate) & $202 \pm 10$ & $205 \pm 11$ & $210 \pm 10$ & $211 \pm 9.0$ \\
\hline Fructose (mmol/ejaculate) & $11 \pm 0.1$ & $13 \pm 0.9$ & $14 \pm 1.1^{\mathrm{a}}$ & $15 \pm 0.1^{\mathrm{a}}$ \\
\hline
\end{tabular}

See footnote to Table 2 for normal ranges. ${ }^{\mathrm{a}} P<0.05$ vs baseline; ${ }^{\mathrm{b}} P<0.05$ vs 3 months.

testosterone. In fact, integrity of gonadotroph function is likely required to obtain the recovery of gonadal function after PRL suppression. It was suggested that gonadal dysfunction in males with prolactinoma could turn from functional modification into irreversible damage in patients with large tumors and severe testosterone deficiency (28). The improvement of NPT results, libido and potency (earlier in patients treated with $\mathrm{CAB}$ than in those treated with BRC) clearly demonstrated that hyperprolactinemia influences male sexual function.

In conclusion, the results of this study show that treatment with $\mathrm{CAB}$ for 6 months is successful in normalizing serum PRL levels and in rapidly restoring gonadal function in men with prolactinoma, with an excellent tolerability. Thus, CAB could be successfully employed in the treatment of male hyperprolactinemic hypogonadism.

\section{References}

1 Carter JN, Tyson JE, Tolis G, Van Vliet S, Faiman C \& Friesen HG. Prolactin-secreting tumors and hypogonadism in 22 men. New England Journal of Medicine 1978299 847-852.

2 Segal S, Yaffe H, Laufer N \& Ben-David M. Male hyperprolactinemia: effects in fertility. Fertility and Sterility 197932 556-561.
3 Thorner MO, McNeilly AS, Hagan C \& Besser GM. Long-term treatment of galactorrhoea and hypogonadism with bromocriptine. British Medical Journal 19742 419-422.

4 Ambrosi B, Bara R, Travaglini P, Weber G, Beck-Peccoz P, Rondena $\mathrm{M}$ et al. Short communication: Study of the effects of bromocriptine on sexual impotence. Clinical Endocrinology 19777 417-421.

5 Hovatta O, Koskimies AI, Ranta T, Stenman UH \& Seppala M. Bromocriptine treatment of oligospermia: a double blind study. Clinical Endocrinology $197911377-382$.

6 Vance M, Evans W \& Thorner M. Bromocriptine. Annals of Internal Medicine $198410078-91$.

7 Schettini G, Lombardi G, Merola B, Colao A, Miletto P, Caruso $\mathrm{E}$ et al. Rapid and long-lasting suppression on prolactin secretion and shrinkage of prolactinomas with improved tolerability after injection of long-action repeatable form of bromocriptine (Parlodel LAR). Clinical Endocrinology 199033 161-169.

8 Merola B, Colao A, Caruso E, Sarnacchiaro F, Lancranjan I, Lombardi $\mathrm{G}$ et al. Effectiveness and long-term tolerability of the slow release oral form of bromocriptine on tumoral and nontumoral hyperprolactinemia. Journal of Endocrinological Investigation $199215173-176$.

9 Colao A, Merola B, Sarnacchiaro F, Di Sarno A, Landi ML, Marzullo P et al. Comparison among different dopamine-agonists of new formulation in the clinical management of macroprolactinomas. Hormone Research $199544222-228$.

10 Colao A, De Rosa M, Sarnacchiaro F, Di Sarno A, Landi ML, Iervolino E et al. Chronic treatment with CV 205-502 restores the gonadal function in hyperprolactinemic males. European Journal of Endocrinology 1996135 548-552.

11 Ferrari C, Barbieri C, Caldara R, Mucci M, Codecasa F, Paracchi A 
et al. Long-lasting prolactin lowering effect of cabergoline, a new dopamine agonist, in hyperprolactinemic patients. Journal of Clinical Endocrinology and Metabolism 198663 941-945.

12 Ciccarelli E, Giusti M, Miola A, Potenzoni F, Sghedoni D, Camann F et al. Effectiveness and tolerability of long-term treatment with cabergoline, a new long-lasting ergoline derivative, in hyperprolactinemic patients. Journal of Clinical Endocrinology and Metabolism $198969725-728$

13 Ferrari C, Mattei A, Melis GB, Paracchi A, Muratori M, Faglia G et al. Cabergoline: long-acting oral treatment of hyperprolactinemia disorders. Journal of Clinical Endocrinology and Metabolism 198969 1201-1206.

14 Webster J. Piscitelli G, Polli A, D’Alberton A, Falsetti L, Ferrari C et al. Dose-dependent suppression of serum prolactin by cabergoline in hyperprolactinemia: a placebo controlled, double blind, multicentric study. Clinical Endocrinology 199237 534-541.

15 Webster J, Piscitelli G, Polli A, Ferrari C, Ismail I, Scanlon MF, for the Cabergoline Comparative Study Group. A comparison of cabergoline and bromocriptine in the treatment of hyperprolactinemic amenorrhea. New England Journal of Medicine 1994331 904-909.

16 Biller BMK, Molitch ME, Vance ML, Baker K, Cannistraro B, Davis KR et al. Treatment of prolactin-secreting macroadenoma with once-weekly dopamine agonist cabergoline. Journal of Clinical Endocrinology and Metabolism 199681 2338-2343.

17 Colao A, Di Sarno A, Sarnacchiaro F, Ferone D, Di Renzo G, Merola B et al. Prolactinomas resistant to standard dopamine agonists respond to chronic cabergoline treatment. Journal of Clinical Endocrinology and Metabolism 199782 876-883.

18 World Health Organization. Laboratory Manual for the Examination of Human Semen and Semen-Cervical Mucus Interaction. World Health Organization, Cambridge University Press, 1993.

19 De Rosa M, Amalfi B, Mennitti M, Zarrilli S \& Lombardi G. The usefulness of new tests in the evaluation of the ejaculate. In Progress in Reproductive Medicine. Diagnosing Male Infertility, vol 15, pp 19-26. Eds GM Colpi \& D Pozza. Basel: Karger.
20 Bradley WE, Timm GW, Gallagher JM \& Johnson BK. New method for continuous measurement of nocturnal penile tumescence and rigidity. Urology $1985264-8$.

21 Bancroft J \& Malone N. The clinical assessment of erectile dysfunction: a comparison of nocturnal penile tumescence monitoring and intracavernosal injections. International Journal of Impotence Research 19957 123-126.

22 Strolin-Benedetti M, Dostert P, Barone D, Efthymiopoulos C, Peretti $\mathrm{G} \&$ Roncucci R. In vivo interaction of cabergoline with rat brain dopamine receptors labelled with $\left[{ }^{3} \mathrm{H}\right] \mathrm{N}-n$-propylnorapomorphine. European Journal of Pharmacology 1990187 399-408.

23 Hondo E, Kurohmaru M, Sakai S, Ogawa K \& Hayashi Y. Prolactin receptor expression in rat spermatogenic cells. Biology of Reproduction 199552 1284-1290.

24 Bartke AJ. Effects of prolactin and luteinizing hormone on the cholesterol stores in the mouse testis. Journal of Endocrinology $197149317-320$.

25 Hafiez AA, Bartke A \& Lloyd CW. The role of prolactin in the regulation of testis function: the synergistic effects of prolactin and luteinizing hormone on the incorporation of $\left[{ }^{1-14} \mathrm{C}\right]$ acetate into testosterone and cholesterol by testes from hypophysectomized rats in vitro. Journal of Endocrinology 197253 223-226.

26 Park SK, Keenan MW \& Selmanoff M. Graded hyperprolactinemia first suppresses LH pulse frequency and then pulse amplitude in castrated male rats. Neuroendocrinology. 199358 448-453.

27 Bohnet HG, Dahlen HG, Wuttke W \& Schneider HPG. Hyperprolactinemic anovulatory syndrome. Journal of Clinical Endocrinology and Metabolism $197642132-143$.

28 Delgrange E \& Donckier J. Gonadal dysfunction in males with prolactinoma: from functional modification to irreversible damage? European Journal of Endocrinology 1997136630.

Received 6 June 1997

Accepted 15 December 1997 